\title{
Topónimos de base Sarand- e Serant-: unha hipótese etimolóxica común ${ }^{1,2}$
}

\author{
Gonzalo Hermo González \\ Instituto da Lingua Galega (ILG) / Universidade de Santiago de Compostela (USC) \\ gonzalo.hermo@gmail.com
}

\begin{abstract}
Resumo:
Este traballo ten por obxectivo abordar a análise etimolóxica dos topónimos de base Sarand- (Sarandeses, Sarandin, Sarandón e Sarandós) e Serant- (Serantellos e Serantes). Para a análise do corpus bótase man das fontes existentes, refutando as diferentes propostas etimolóxicas en base á estrutura lingüística e á presenza documental de cada forma. A hipótese que aquí defendo é que todos estes topónimos teñen unha orixe común, que asenta nun antigo radical indoeuropeo especialmente produtivo en Galicia: *ser-, *sor- 'fluír, discorrer'.
\end{abstract}

\section{Palabras chave:}

Toponimia, etimoloxía, léxico, hidronimia, paleoeuropeo, lingüística histórica, morfoloxía.

\begin{abstract}
:
The main aim of this paper is to analyze the etymology of the place names Serantes, Sarandós and their lexical family: Sarandeses, Sarandín, Sarandón, Sarandós, Serantellos and Serantes. Authorized sources are used for the analysis of the corpus, refuting the different etymological proposals based on the structure and documentary presence of each place name. I will try to show that all these place names have the same origin, which is an old european lexeme that abounds in Galicia: *ser-, *sor-, 'to flow, to gush'.
\end{abstract}

\section{Key words:}

Place names, etymology, lexicon, hydronymy, old european, historical linguistics, morfology.

1 A investigación que conduciu á publicación deste artigo foi realizada ao abeiro dunha bolsa-contrato do programa FPU do Ministerio de Cultura, Educación e Deporte, acadada na convocatoria de 2012.

2 Gustaríame agradecerlles a María Álvarez de la Granja as precisións terminolóxicas con que tivo a ben enriquecer este traballo, a Xosé Luís Regueira que me proporcionase información inédita do Dicionario de pronuncia da lingua galega a propósito de Sarandós e aos correctores anónimos do artigo as achegas e puntualizacións con que contribuíron a melloralo. 


\section{Introdución}

Este traballo parte, na súa matriz primeira, da vontade de esclarecer a orixe do topónimo Sarandón. En vista de que as solucións etimolóxicas ofrecidas ata o momento resultaban pouco satisfactorias, a investigación orientouse a suxerir un escenario de traballo novo, volcado na súa vinculación con outros topónimos formalmente próximos. Desa hipótese inicial xurdiu a localización de dúas bases toponímicas, Sarand- e Serant-, a cuxa análise conxunta se encamiña o resultado final da investigación que se reflicte neste artigo.

A primeira tarefa que nos propuxemos foi, pois, acoutar as formas lingüísticas que representaban esas bases e situalas no espazo. Neste campo resultounos de especial proveito o NG e mais o PTG. Con todo, o desenvolvemento da pescuda levounos fóra dos límites da Galicia administrativa, e mesmo da área galegófona, polo que tamén foron obxecto de consulta inventarios de topónimos de España, Portugal e dos territorios irredentos de fala galega, nomeadamente o de Varela Aenlle (2000).

Unha vez delimitadas as formas lingüísticas obxecto de análise e localizadas, procuramos bibliografía que as tratase do punto de vista etimolóxico. O groso desas achegas diríxese a situar os étimos ben en material léxico latino, ben en material antroponímico. Dado que ningunha desas propostas se presentaba como definitiva, nunha primeira parte do traballo, centrámonos en discutilas de acordo con dous criterios fundamentais: o lingüístico e o documental. No plano estrutural, sinalamos aquelas eivas ou puntos fracos das distintas hipóteses que asentasen na incongruencia coa evolución fonética e morfolóxica regular da lingua desde o latín; pola súa parte, no eido documental, achegamos, cando cumpría, a ausencia ou escaseza de rexistros antigos. Sempre que foi posible, tivemos en consideración, aínda, un terceiro criterio: a parca ou nula produtividade en galego dos étimos propostos.

Desbotadas todas estas teorías, encamiñámonos a propoñer unha etimoloxía común para ambas as series de topónimos que bebeu da hidrotoponimia indoeuropea galega, apoiándonos en contribucións de lingüistas como Hans Krahe, Juan J. Moralejo, Edelmiro Bascuas ou Francisco Villar. Para tal fin, botamos man da propia morfoloxía das formas, da abundancia de sobreviventes da mesma raíz indoeuropea na onomástica galega e de probas epigráficas. A análise, neste punto, realizouse en tres niveis morfolóxicos distintos, comezando polo radical, continuando pola sufixación primaria e rematando polas desinencias secundarias. 
Por último, incorporamos unha breve síntese das conclusións que se extraeron do proceso de investigación, remarcando aqueles aspectos centrais da abordaxe e subliñando a liña argumental que conduciu a propoñer unha etimoloxía determinada e non outra.

\section{Topónimos de base Sarand- e Serant-}

Tomando como referencia o NG, detectamos a existencia dunha serie de topónimos de base Sarand- e unha outra de base Serant-. A primeira está constituída polas formas Sarandeses, Sarandín, Sarandón e Sarandós, que dan nome a oito entidades de poboación espalladas ao longo do país. A segunda fórmana os resultados Serantes e Serantellos, cun total de dezaseis entidades diferentes. Partindo do NG, pero completándoo con información tirada do $\mathrm{PTG}^{3}$, podemos establecer a seguinte relación de localidades:

\begin{tabular}{l|l|l|l|l|l} 
Topónimo & Tipoloxía & Parroquia & Concello & Comarca & Provincia \\
$\begin{array}{l}\text { A Ponte de } \\
\text { Sarandón }\end{array}$ & Lugar & $\begin{array}{l}\text { San Mamede de } \\
\text { Ribadulla }\end{array}$ & Vedra & Santiago & A Coruña \\
\hline $\begin{array}{l}\text { San Miguel de } \\
\text { Sarandón }\end{array}$ & Parroquia & - & Vedra & Santiago & A Coruña \\
\hline $\begin{array}{l}\text { San Pedro de } \\
\text { Sarandón }\end{array}$ & Parroquia & - & Vedra & Santiago & A Coruña \\
\hline Sarandeses & Lugar & $\begin{array}{l}\text { Santaia de } \\
\text { Rairiz (Santaia) }\end{array}$ & Santiso & $\begin{array}{l}\text { Terra de } \\
\text { Melide }\end{array}$ & A Coruña \\
\hline Sarandín & Lugar & $\begin{array}{l}\text { O Barón } \\
\text { (San Fiz) }\end{array}$ & O Carballiño & O Carballiño & Ourense \\
\hline Sarandón & Lugar & $\begin{array}{l}\text { San Miguel de } \\
\text { Sarandón }\end{array}$ & Vedra & Santiago & A Coruña \\
\hline Sarandós & Lugar & $\begin{array}{l}\text { San Román de } \\
\text { Montoxo }\end{array}$ & Cedeira & Ferrol & A Coruña \\
\hline $\begin{array}{l}\text { Sarandós } \\
\text { (Santa María) }\end{array}$ & Parroquia & - & Abegondo & A Coruña & A Coruña \\
\hline
\end{tabular}

Táboa 1. Toponimia maior de base Sarand-

3 A Comisión de Toponimia da Xunta de Galicia atópase nestes momentos revisando o NG á luz dos datos que se foron engadindo ao PTG. No que atinxe os topónimos que neste traballo interesan, o PTG recolle dúas entidades de poboación máis ca o Nomenclátor, nomeadamente os lugares de Serantes, en Santa Uxía de Fao (Touro) e A Ponte de Sarandón, en San Mamede de Ribadulla (Vedra), que incorporamos á nosa análise. Ambas as localidades figuraban xa como núcleos de poboación no século XIX (DMadoz v. XIII: 839, v. XIV: 193). 


\begin{tabular}{|c|c|c|c|c|c|}
\hline Topónimo & Tipoloxía & Parroquia & Concello & Comarca & Provincia \\
\hline Serantellos & Lugar & $\begin{array}{l}\text { Castrelo } \\
\text { (Santa Cruz) }\end{array}$ & Cambados & Salnés & Pontevedra \\
\hline Serantellos & Lugar & $\begin{array}{l}\text { Serantes } \\
\text { (San Salvador) }\end{array}$ & Ferrol & Ferrol & A Coruña \\
\hline Serantes & Lugar & $\begin{array}{l}\text { Baión } \quad \text { (San } \\
\text { Xoán) }\end{array}$ & $\begin{array}{l}\text { Vilanova de } \\
\text { Arousa }\end{array}$ & Salnés & Pontevedra \\
\hline Serantes & Lugar & $\begin{array}{l}\text { Fao } \quad \text { (Santa } \\
\text { Uxía) }\end{array}$ & Touro & Arzúa & A Coruña \\
\hline Serantes & Lugar & $\begin{array}{l}\text { Moraime } \\
\text { (San Xulián) }\end{array}$ & Muxía & Fisterra & A Coruña \\
\hline Serantes & Lugar & $\begin{array}{l}\text { O Vicedo } \\
\text { (Santo Estevo) }\end{array}$ & O Vicedo & $\begin{array}{l}\text { A Mariña } \\
\text { Occidental }\end{array}$ & Lugo \\
\hline Serantes & Lugar & $\begin{array}{l}\text { San Cosme de } \\
\text { Outeiro }\end{array}$ & Outes & Noia & A Coruña \\
\hline Serantes & Lugar & $\begin{array}{l}\text { Serantes } \\
\text { (Santaia) }\end{array}$ & Santiso & $\begin{array}{l}\text { Terra de } \\
\text { Melide }\end{array}$ & A Coruña \\
\hline Serantes & Lugar & $\begin{array}{l}\text { Veiga } \\
\text { (Santo Adrao) }\end{array}$ & Ortigueira & Ortegal & A Coruña \\
\hline $\begin{array}{l}\text { Serantes de } \\
\text { Abaixo }\end{array}$ & Lugar & $\begin{array}{l}\text { Oza } \\
\text { (San Breixo) }\end{array}$ & Carballo & Bergantiños & A Coruña \\
\hline $\begin{array}{l}\text { Serantes do } \\
\text { Medio }\end{array}$ & Lugar & $\begin{array}{l}\text { Oza } \\
\text { (San Breixo) }\end{array}$ & Carballo & Bergantiños & A Coruña \\
\hline $\begin{array}{l}\text { Serantes } \\
\text { (San Salvador) }\end{array}$ & Parroquia & - & Ferrol & Ferrol & A Coruña \\
\hline $\begin{array}{l}\text { Serantes } \\
\text { (Santaia) }\end{array}$ & Parroquia & - & Santiso & $\begin{array}{l}\text { Terra de } \\
\text { Melide }\end{array}$ & A Coruña \\
\hline $\begin{array}{l}\text { Serantes } \\
\text { (Santa María) }\end{array}$ & Parroquia & - & Laxe & Bergantiños & A Coruña \\
\hline $\begin{array}{l}\text { Serantes } \\
\text { (San Tomé) }\end{array}$ & Parroquia & - & Leiro & O Ribeiro & Ourense \\
\hline $\begin{array}{l}\text { Serantes } \\
\text { (San Xián) }\end{array}$ & Parroquia & - & Oleiros & A Coruña & A Coruña \\
\hline
\end{tabular}

Táboa 2. Toponimia maior de base Serant-

A recollida parcial que ofrece o PTG, aínda en construción, permítenos confirmar que as bases Sarand- e Serant- contan tamén con representantes na toponimia menor, malia que os resultados que a aplicación presenta non engaden ningunha forma lingüística nova. Así pois, a meirande parte destes microtopónimos atopan a súa razón de ser nos topónimos maiores arriba enumerados: Camiño de Serantellos, Lavadoiro de Sarandón, etc. Cómpre mencionar aquí aqueloutros cuxa motivación 
orixinal non é tan clara, pois non se dá unha relación de dependencia con ningún deses lugares: un bosque de nome Serantes, en Vilouzás (Paderne, comarca de Betanzos, A Coruña) e dous terreos chamados Sarandín (Santiago de Anllo, San Amaro, comarca do Carballiño, Ourense) e Serantes (Santa María da Pedra, Cariño, Ortegal, A Coruña). Velaí un mapa cos puntos onde se atopa algún representante das devanditas bases, ora topónimo maior, ora microtopónimo:

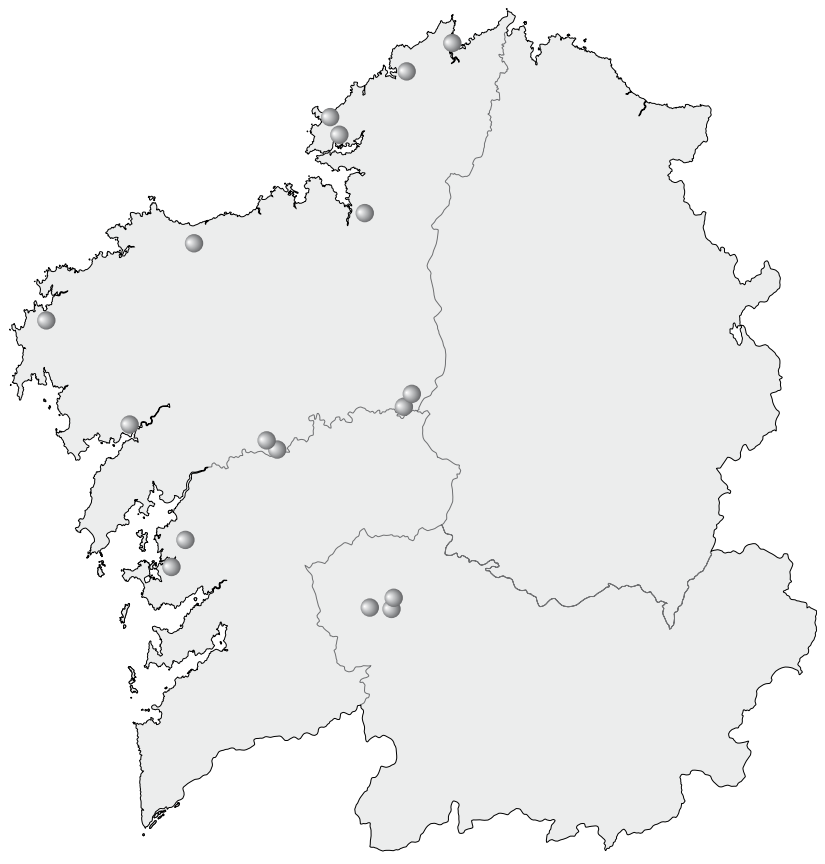

Mapa 1. Toponimia maior e microtoponimia de base Sarand- e Serant- (PTG).

O Mapa1 debúxanos un reparto de Sarand- e Serant- ao longo da metade occidental do país. Con todo, fóra da Galicia administrativa, pero aínda en territorio galegófono, concretamente no Eo-Navia, atopamos o lugar e a parroquia de Serantes, no municipio de Tapia de Casarego ${ }^{4}$ e mais a freguesía e lugar de Serandías, en Boal. Este último topónimo resulta de especial interese, xa que supón unha base nova, Serand-, a medio camiño entre as dúas comentadas, pero sen dúbida relacionada con elas. Teremos ocasión de analizala ao longo do traballo.

4 As localidades eonaviegas citámolas polas formas estandarizadas que propón Varela Aenlle (2000). 
Aínda en Asturies, pero xa en territorio de fala asturiana, atopamos a aldea de Serantes, en Xixón, e mais o lugar de Serandi, en Proaza, da mesma base ca Serandias, por onde transcorre o río homónimo. Máis lonxe queda un caserío tamén chamado Serantes, no municipio de Aldea del Fresno, provincia de Madrid. En Portugal non existe exemplo ningún destas bases.

Serantes rexístrase, ademais, como orónimo e hidrónimo. Como orónimo, dá nome a un monte da comarca de Bilboaldea, situado ao pé da ría de Bilbo, en Bizkaia, Euskadi. Como hidrónimo aparece como denominación alternativa ao río Tol, que atravesa os lugares de Serantes (Serantes, Tapia de Casarego, Asturies) e Tol (Tol, Castropol, Asturies).

Na tradición onomástica galega, ambas as cadeas de nomes foron tratadas de xeito diferenciado. De feito, a bibliografía de que dispomos tende a analizar cada forma por separado, sen establecer pontes lingüísticas con outras solucións formalmente próximas. A nosa proposta oriéntase precisamente no sentido inverso, argumentando a prol dun étimo común. Nas páxinas seguintes iremos recollendo as hipóteses lanzadas nos estudos toponomásticos, de Sarmiento á actualidade, e sinalaremos os problemas lingüísticos que presentan. Finalmente, artellaremos unha tese de noso que, non obstante, asenta na xenealoxía de estudo da hidrotoponimia prelatina en Galicia.

\section{Hipóteses de orixe latina e xermánica}

\subsection{A opinión de Sarmiento}

Na súa viaxe de 1754, frei Martín Sarmiento, pai da onomástica galega, ocúpase dalgúns topónimos que neste traballo tocan: "Estoy en que Sarandon, Sarandones y Zarandones, Serantes, Senra, Seara, Samenaria, Sada, Saa, etc., todo viene de Sero, is, sevi, satum, semino, seminaria, etc." (OELG v. I: 177). Hoxe sabemos que eses nomes de lugar teñen orixes diversas que nada teñen que ver co latín sero 'plantar, sementar'. Senra e Seara, formas vivas na fala actual co sentido de 'campo sementado de trigo ou outros cereais' ou co máis específico de 'parcela de monte roturada para sementar trigo ou outros cereais' (DRAG; Navaza 2007: 57), deben proceder dun lexema prerromano *senara 'labrado á parte', talvez celta (DCECH v. V: 221). Saa provén do xermánico sala 'quinta, casal' (ELH: 538-539) e Sada é probablemente de orixe árabe (Frías Conde 2002: 74). Pola súa parte, Samenaria era a solución antiga do moderno Samieira, de etimoloxía discutida, aínda que é seguro que a relación non a establece coa secuencia de topónimos que Sarmiento propón, senón con Samos ou Samoedo (Moralejo Álvarez 2009: 69). 
No que máis nos interesa, as solucións recollidas polo frade como Sarandones e Zarandones son formas deturpadas de Sarandós. Mais nin Sarandós, nin Sarandón nin Serantes proveñen do latín sero. Aínda que a tese de Sarmiento foi rexeitada pola práctica totalidade da toponomástica moderna, hai quen, como Frutos Fernández, continúa a recoñecerlle validez. Segundo Fernández (2007: 278-280, 284-285), Serantes, Sarandín e talvez Sarandón poden estar relacionados co sero latino a través do participio de presente serens, serentis co sentido de 'sementado'. Porén, esta idea presenta dous problemas fundamentais. O primeiro é de orde fonética, pois de SERENTES debera xurdir unha forma romance *Serentes e, de producirse unha acción disimilatoria, como supoñemos que coida Fernández, o lóxico é que afectase á pretónica (*Sarentes) e non á tónica, fenómeno que se reflicte nas pronuncias populares sacreto, nacesitar ou taléfono. Máis complicado aínda é facer derivar Sarandín e Sarandón dese mesmo participio SERENTES.

O segundo é que non temos constancia de que o verbo sero deixara herdanza en galego. Así, os lexemas con significado análogo na nosa lingua teñen efectivamente orixe latina, pero non proceden dese verbo: sementar é deverbal de semente, do latín SEMĚNTIS 'sementeira', 'epoca da sementeira', e semear provén de SEMIINARE 'sementar', derivado de SĒMEN 'semente' (DCECH v.V: 328). Non demos atopado ningunha peza léxica galega que se explique a partir dese verbo. Se, como cre Fernández (2007: 285), Serantes ten carácter agrotoponímico, mellor sería facelo derivar do prerromano * senara, que si foi produtivo en galego (*senara $>$ seara, senra), aínda que a evolución formal tampouco é satisfactoria.

Malia que esta tese é dificilmente defendible en termos lingüísticos, consideramos que Sarmiento, e canda el Fernández, tiveron o acerto de (a) buscaren unha orixe común para a tríade Sarandón/Sarandós/Serantes e (b) afirmaren que a súa procedencia asenta no léxico común, e non en material onomástico preexistente, como veremos que defenden outros autores a continuación.

\subsection{As hipóteses antroponímicas}

Moitos dos especialistas que se achegaron a algunha destas formas acreditan na súa procedencia deonomástica, isto é, pensan que derivan de nomes persoais de antigos propietarios ou posuidores rurais da Alta Idade Media. Con certeza, é este un proceso de creación toponímica altamente rendible, cun mecanismo de evolución case que constante: son nomes que proveñen dunha estrutura nominal con núcleo vīlla ou FUNDUS modificado polo antropónimo en caso xenitivo. Vilaúxe, poñamos por caso, procede dunha antiga forma *VīLLA URSI 'vila de Ursus', dun nome persoal latino 
Ursus, á súa vez creado sobre o substantivo común ursus 'oso' (Piel 1984: 22). Non obstante, na meirande parte dos casos, co paso do tempo, o elemento nuclear VīLLA (ou outro semanticamente afín) acaba esvaecendo, de tal maneira que o topónimo, no seu resultado moderno, só reflicte a forma antroponímica. Así acontece, como tivemos a ocasión de comentar noutro traballo (Hermo González 2013: 60-62), con Chorente < (vīlla) FLORENTI(I) 'vila de Florentius', Ourille < *(Vīlla) AURELII 'vila de Aurelius'ou Ourolo/Ourol < *(villa) AURIoli 'vila de Auriolus'.

Unha das achegas que debemos ter en consideración é a que verten Piel e Kremer no Hispano-gotisches Namenbuch a propósito de Sarandín (HGNB 222). Os autores suxiren a posibilidade de que sexa unha formación do xermánico *sa(la)'quintal, granxa' e mais o antropónimo Randinus, atestado en Galicia desde o ano 816 (CODOLGA). Pola súa parte, Randinus é unha formación híbrida composta do xermánico rand- 'beira do escudo' e mais do sufixo latino -ĩNus, que indica pertenza, procedencia, materia ou relación (HGNB 222). Así pois, Sarandín proviría dun hipotético *(VĪLLA) SA(L)A-RAND-īNI, non documentado.

Aínda que Piel e Kremer non citan esta posibilidade, Pensado (OELG v. I: 178) apunta que a mesma hipótese que achegan para Sarandín é aplicable a Sarandón, se partimos da forma antroponímica Randon, que se rexistra en Galicia desde o ano 910 (CODOLGA), xerada sobre a mesma base rand- pero co sufixo latino -ō, - ŌNIS. Con todo, Sarandón sería explicable desde o acusivo *SA(L)A-RAND-ONE(M), mais non desde o xenitivo *SA(L)A-RAND-ONIS, caso que esperamos atopar por detrás dun topónimo deantroponímico, como vimos, salvo que aventuremos un xenitivo analóxico *SA(L)A-RAND-ONI ou unha forma romanceada *(VĪLLA DE) SA(L)A-RANDONE(M). Sexa como for, Pensado rexeita, cremos que acertadamente, ambas as hipóteses, argüíndo a ausencia de documentación e mais o feito, nada desprezable, de que os rexistros documentais máis antigos ofrecen xa a forma Sarandon (a. 914), nunca *Saarandon ou similares (OELG 178).

O propio Pensado postula outras opcións que, no entanto, non cuestionan a hipótese antroponímica. Así, explica Serantes a partir do nome persoal latino SARRANATES, que tira do Eigennamen de Schulze, con acentuación proparoxítona SARRÁNATES $>*$ Sarrãates $>*$ Sarrantes $>$ Sarantes $>$ Serantes, pola frecuencia da alternancia de -rr- / -r-. Porén, Pensado non ten en conta que a devandita alternancia é frecuente en material léxico e onomástico de orixe prerromana, pero non no latino (Moralejo Álvarez 2008: 144; Villar 1993). Ademais, non temos constancia documental de que o antropónimo Sarranates entrase en Galicia; moito menos das fases intermedias que el postula. O propio autor é plenamente consciente das dificultades que presenta a súa proposta cando afirma que "es hipótesis arriesgada" (OELG 178). 
Tamén García Arias (2005: 480, 482, 508) se suma á tese deonomástica e defende cadanseu étimo antroponímico para Serantes, Serandias e Serandi. Serantes faino derivar de SERUS, nome persoal latino recollido por Kajanto; Serandías de *SERANDINUS, formado sobre *SERANDUS, variante reconstruída de SERANDIUS, que citan Solin/ Salomies; directamente dese mesmo *SERANDUS procedería Serandi.

As evolucións lingüísticas que esixe a proposta deste investigador, mesmo sendo posibles, son altamente especulativas. Se Serantes procede de SERUs, cognomen que se declina pola segunda (Kajanto 1982: 295), ten que ser por vía dunha forma con xenitivo analóxico en -IS (*SERANTIS), contra o esperable, que sería -I. Pola súa parte, o resultado Serandías tampouco se pode explicar desde ningún caso da segunda declinación, a que pertencería ese hipotético étimo * SERANDINUS. Menos problemas presenta a evolución *(VILLA) SERANDI $>$ Serandi, aínda que hai que reconstruír unha variante * SERANDUS a partir do SERANDIUS que Solin/Salomies recollen ( $c f r$. epígrafe 4.4). Por maior abastanza, ningún dos étimos propostos aparece na documentación medieval galaica empregado como nome persoal (CODOLGA).

Do punto de vista da lingüística diacrónica, o feito de remitir estes topónimos a senllos étimos antroponímicos obríganos a botar man en demasiadas ocasións de irregularidades e evolucións anómalas. Por outra banda, a presenza documental deses antropónimos non é un elemento que xogue a favor da súa consideración como étimos. Consecuentemente, está xustificado abandonar a hipótese antroponímica e ir procurar no material léxico a orixe de todas estas formas, máxime cando a lóxica nos incita a pensar que se trata de solucións derivadas mediante sufixación dunhas bases Sarand- e Serant-: Sarand-ón, Sarand-eses, Serant-ellos...

Ben é certo que todos estes topónimos carecen de artigo (non hai un *O/A Sarandín ou $*$ Os/As Serantes), o que podería interpretarse como un indicio a prol do seu carácter deantroponímico. Pénsese que un vestixio claro de que un topónimo procede dun termo usado na lingua con valor apelativo é a presenza do artigo. Mais isto non acontece coa toponimia delexical de orixe prelatina, onde a conciencia de que o topónimo procede dunha forma do léxico común se perdeu axiña ${ }^{5}$. É por iso

5 A ausencia / presenza do artigo en pares delexicais coma Outeiro / O Outeiro, Castro / O Castro ou Souto / O Souto debe explicarse polo grao de fixación dos elementos léxicos que dan orixe ao topónimo en tanto que identificadores do territorio sen valor apelativo. A existencia de formas con e sen artigo nun mesmo territorio, inscritos, polo tanto, nunha mesma fala local, descarta que a variación responda a un criterio de tipo xeolectal: Outeiro Redondo pero Costa do Outeiro (nomes correspondentes a dúas entidades de poboación da parroquia de Almofrei, no concello de Cotobade), $O$ Castro de Caldelas, nome dunha aldea, pero Castro Caldelas, nome da parroquia e do concello que abranguen esa aldea, etc. (NG). 
que a hidrotoponimia prerromana, onde cremos que hai que ir buscar a orixe dos nosos topónimos, non presenta, polo xeral, artigo: Xallas, Ulla, Parada de Sil, Riba de Miño, Tambre, Té ... (Navaza 2011: 5).

\section{Camiñando cara a un étimo común: a raíz *ser- e a hidrotoponimia indoeuropea en Galicia}

\subsection{A documentación medieval}

Se botamos unha ollada aos datos que nos proporcionan o TMILG, o CODOLGA e o ITGM, descubriremos que os topónimos de base Serant-, isto é, Serantes e Serantellos, aparecen maioritariamente recollidos na documentación medieval con $<$ a $>$ gráfico átono, o que nos fai supoñer que o actual resultado Serant- procede, por disimilación, dunha antiga base Sarant-. En termos absolutos, a distribución Sarantes/Serantes é a seguinte:

\begin{tabular}{c|c|c|c|c|c|c|c} 
& XI & XII & XIII & XIV & XV & s.a. & Total \\
Sarantes & $100 \%$ & $77,14 \%$ & $98,46 \%$ & $100 \%$ & 71,43 & $100 \%$ & $\mathbf{9 1 , 3 4 \%}$ \\
& $(3 / 3)$ & $(27 / 35)$ & $(64 / 65)$ & $(2 / 2)$ & $(5 / 7)$ & $(15 / 15)$ & $(116 / 127)$ \\
\hline Serantes & $0 \%$ & $22,86 \%$ & $1,54 \%$ & $0 \%$ & 28,57 & $0 \%$ & $\mathbf{8 , 6 6 \%}$ \\
& $(0 / 0)$ & $(8 / 35)$ & $(1 / 65)$ & $(0 / 2)$ & $(2 / 7)$ & $(0 / 15)$ & $(11 / 127)$ \\
\hline
\end{tabular}

Táboa 3. Sarantes fronte a Serantes na documentación medieval.

Nos textos da Idade Media ás veces é difícil coñecer a localidade concreta que o amanuense está aludindo cando escribe un topónimo con referentes múltiples, máxime cando en boa parte da documentación atopamos os nomes de lugar empregados como identificadores persoais, por exemplo, en Nuno Iohannis de Sarantes (CODOLGA). Esa ambigüidade desaparece frecuentemente cando a entidade referida é unha parroquia, pois o habitual é que apareza mencionada a advocación relixiosa, en fórmulas do tipo Santa María de Serantes. Para ilustrar os datos anteriores con localidades ben delimitadas, recollemos, a seguir, os rexistros que o TMILG e o CODOLGA nos devolven das freguesías de San Salvador de Serantes e San Tomé de Serantes onde figura a referencia ao santo titular e, polo tanto, a correspondencia é unívoca:

6 A devandita xeneralización é aplicable á hidrotoponimia, isto é, á toponimia derivada de nomes de ríos, non á hidronimia propiamente dita, onde o uso do artigo si é frecuente como resultado dunha elipse do núcleo río: $O$ (rio) Tambre, $O$ (rio) Sar, etc. 


\begin{tabular}{c|c} 
Ano & Topónimo \\
1114 & sancti Saluatoris de Sarantes \\
\hline 1132 & sancti Saluatoris de Serantes \\
\hline 1195 & sancti Saluatoris de Sarantes \\
\hline 1226 & sancti Saluatoris de Sarantes \\
\hline 1226 & sancti Saluatoris de Sarantes \\
\hline 1284 & San Salvador de Serantes \\
\hline 1291 & San Saluador de Sarantes \\
\hline 1488 & San Saluador de Sarantes \\
\hline
\end{tabular}

Táboa 4. San Salvador de Serantes (Ferrol, comarca de Ferrol, A Coruña) nos textos da Idade Media.

\begin{tabular}{c|c} 
Ano & Topónimo \\
1290 & San Thome de Sarantes \\
\hline 1413 & san Thome de Sarantes \\
\hline 1417 & san Tome de Serantes \\
\hline 1491 & santo Thome de Sarantes \\
\hline
\end{tabular}

Táboa 5. San Tomé de Serantes (Leiro, O Ribeiro, Ourense) nos textos da Idade Media.

Engadimos, ademais, os datos que tiramos do ITGM, que localiza a toponimia a partir das referencias documentais da Idade Media, para o lugar de Serantes, freguesía de San Cosme de Outeiro:

\begin{tabular}{c|lc|l} 
Ano & \multicolumn{1}{|c|}{ Topónimo } & Ano & \multicolumn{1}{c}{ Topónimo } \\
1126 & Sarantes & 1217 & Alfonsus Pelagii de Sarantes \\
\hline 1143 & Sarantes & 1218 & Anfonsus Pelagii de Sarantes \\
\hline 1143 & Sarantes & 1228 & Sarantes \\
\hline 1143 & Sarantes & 1247 & Dominicus Pelaiz de Sarantes \\
\hline 1143 & Sarantes & 1247 & Martinus Iohannis de Sarantes \\
\hline 1160 & Sarantes & 1247 & Martinus Pelaiz de Sarantes \\
\hline 1212 & Alfonsus Pelaiz de Sarantes & 1247 & Petrus de Sarantes \\
\hline 1212 & Martinus Ueliu de Sarantes & &
\end{tabular}

Táboa 6. Serantes (San Cosme de Outeiro, Outes, comarca de Noia, A Coruña) nos textos da Idade Media. 
Do actual Serantellos, as devanditas aplicacións achegan 32 rexistros das solucións gráficas $<$ Sarantelos $>$, $<$ Sarantelios $>$, $<$ Sarantelus $>$, $<$ Sarantelius $>$ e $<$ Sarantellius $>$, datadas entre os anos 934 e 1201 (CODOLGA; TMILG), todas elas de base Sarant-. Se, como explicaremos máis adiante ( $c f r$. epígrafe 4.5), Serantellos é un diminutivo de Serantes, daquela a presenza exclusiva da forma Sarantellos, con $a$, na documentación medieval indícanos que este último topónimo tivo que ser xerado sobre unha forma Sarantes, tamén con $a$, e, polo tanto, confirma a nosa sospeita de que a base Serant- é máis tardía. Aínda hoxe as solucións orixinais Sarantellos e Sarantes sobreviven fosilizadas como apelidos, malia que no caso de Sarantes dunha maneira residual fronte ao maioritario Serantes (CAG).

Dos representantes de Sarand- dispomos dunha menor cantidade de atestacións medievais, aínda que os datos con que contamos garanten a supervivencia desa mesma base no tempo desde a segunda metade do século XIII (CODOLGA; TMILG):

\begin{tabular}{c|l} 
ANO & TOPÓNIMO \\
1191 & Michaelis de Sarandon \\
\hline 1191 & Sancti Petri de Sarandon \\
\hline 1228 & scs. Petrus de Sarandon \\
\hline $1229($ ca. $)$ & Sancte Marie de Serandones \\
\hline 1245 & Sancti Michaelis de Sarandon \\
\hline 1270 & Sco. Michaele de Sarandon \\
\hline 1375 & duram dominguez de Sarandom \\
\hline 1375 & S. Miguell de Sarandom \\
\hline 1382 & San Pedro de Sarande \\
\hline 1398 & San miguell de Sarandon \\
\hline 1432 & Ponte Sarandon \\
\hline 1488 & pont Sarandoos \\
\hline
\end{tabular}

Táboa 7. Topónimos de base Sarand- nos textos da Idade Media.

Un único rexistro se afasta da solución moderna e presenta <e> gráfico: Sancte Marie de Serandones, ca. 1229 (CODOLGA). Supoñendo que non se trate dun erro de lectura, esa forma vén demostrar que a acción disimilatoria que conduciu a un resultado Serantes desde o primitivo Sarantes tamén estivo activa para a base Sarand-, aínda que, nesta familia de topónimos, non acabou triunfando. 
En todo caso, as probas documentais da Idade Media permítennos aventurar unha raíz sar-para o conxunto de nomes de lugar de base Serant- (< Sarant-) e Sarand-, un radical que, como veremos a continuación, se atopa ben representado na hidronimia galega.

\subsection{A raíz *ser-, *sor- e a hidro(topo)nimia paleoeuropea en Galicia}

Nun traballo presentado no simposio Lingua e territorio, organizado polo Instituto da Lingua Galega en 2004, Juan J. Moralejo (2008: 299-338) expuxo, con meridiana clareza, os problemas que presenta o establecemento dos sistemas lingüísticos de carácter substratístico do galego, cuxo coñecemento e estudo se presenta como tarefa crucial á hora de coñecermos a etimoloxía de boa parte dos nosos topónimos. Tradicionalmente, víñase considerando que a indoeuropeización de Galicia fora activada pola chegada de pobos celtas no I milenio a.C. Con anterioridade a estas datas, os habitantes do territorio que hoxe configura Galicia debían falar unha ou varias linguas preindoeuropeas de filiación ignota, se cadra emparentadas co vasco ou o ibero. Dun tempo a esta parte, os lingüistas que se ocuparon da cuestión veñen rompendo co esquema que identifica indoeuropeización con celtización, argumentado a favor da antigüidade do substrato indoeuropeo na Gallaecia. Tal é o caso do propio Moralejo (2008: 299-338), cuxa proposta asenta na escaseza e pouca consistencia de elementos preindoeuropeos en galego e mais na existencia dun sistema lingüístico claramente indoeuropeo que se reflicte na hidronimia e que non se pode atribuír ao celta. Certamente, nesa lingua que se conserva nos nomes dos ríos obsérvase unha serie de fenómenos estruturais que descartan que se trate de celta, principalmente a confusión entre /ă/ e / $\breve{o} /$, e que son atribuíbles a un estadio lingüístico do indoeuropeo anterior ás linguas que foron callando dentro da comunidade primitiva indoeuropea (Moralejo Álvarez 2008: 319). O “descubridor" e principal estudoso dese sistema lingüístico, Krahe (1964), que o bautizou co nome de Alteuropäische (en galego antigo europeo ou paleoeuropeo), rexistrou a súa existencia en ríos dunha extensa faixa do continente, desde os Urais ao Mar do Norte e as Illas Británicas, desde o Mar Báltico ata os Alpes, incluídas as penínsulas Ibérica e Itálica.

A pegada paleoeuropea na onomástica galega vén complicar o mapa xenealóxico dos nosos hidrónimos e, canda eles, dos topónimos derivados de raíces hidronímicas, que agora poden remitir a catro sistemas lingüísticos distintos, cronoloxicamente sucesivos e todos eles indoeuropeos. A modo de exemplo, Avia e Avión son nomes de ríos paleoeuropeos, máis remotos, polo tanto, ca Dubra ou Ambía, que xa son celtas. Mais Dubra e Ambía son anteriores aos latinos Anllo ou Riaño, pola súa parte máis antigos ca os xa plenamente romances Río Grande ou Río das Pedras. Ningún destes estratos poden ser ignorado á hora de abordarmos a toponimia galega, pois, 
contra o previsible, a hidro(topo)nimia paleoeuropea sobrevive fosilizada nun número elevadísimo de cursos de auga do país (Bascuas 2002, 2006).

Pois ben, neste traballo acreditamos en que os topónimos da familia de Serantes e Sarandós reflicten, precisamente, un antigo radical indoeuropeo, xa identificado por Krahe (1964) e estudado en Galicia por Bascuas (2008: 529-530) e Moralejo Laso (1980: 161-162): *ser-, *sor- 'fluír, discorrer', recoñecible no sánscrito sara 'río', saráh 'líquido', sarit 'regato' e no latín serum 'soro'. Da primeira forma da raíz, con vogal palatal, achega Krahe os ríos franceses Serre $(<$ Sera), Séran e Cére $(<*$ Serana). Da segunda, con vogal velar, o francés Sarre, alemán Saar, inglés Soar e os galeses Sor e Cwm Sorgwm (Moralejo Laso 1980: 161-162). A esta segunda listaxe podemos engadir os hidrónimos franceses Sarnon, Sarsonne, Sarsoville, Sarthe, Sarton e Sarampion, identificados por Dauzat (1978: 82). Cómpre reparar en que a confusión entre $\breve{o}$ e $a$ en paleoeuropeo, xa comentada, é a que explica neste último grupo a presenza dunha variante *sar- a partir de *sor- (Moralejo Laso 1980: 160).

Volvendo a Galicia, o mesmo Krahe recoñeceu no nome do noso Sar, célebre río que pasa por Santiago, e canda el do seu afluente o Sarela, un herdeiro desa mesma raíz, con idéntica confusión *sor- > *sar-. A eles hai que sumar as 13 entidades de poboación e 4 terras de labradío chamadas Sar que recollen o NG e o PTG. Moralejo Laso (1980: 162) engade ao inventario o hidrónimo Sor, curso de auga que desemboca na ría do Barqueiro. Pola súa parte, Bascuas (2008: 530) fai o propio con Ser, afluente do Navia, Sarria ${ }^{7}$, afluente do Neira e nome dun concello, dúas parroquias e tres lugares agromados en torno a ese curso de auga, Sardiñei$r a$, afluente do Miño e nome dunha zona dos Mallos na cidade da Coruña, Zarzo (med. Sartio), afluente do Mandeo, Sorga, afluente do Arnoia, a illa ribeirense de Sarga, o lugar e parroquia de Mon-serio (Láncara, comarca de Sarria, Lugo) e de Monteseiro, medieval Monte Serio (A Fonsagrada, comarca da Fonsagrada, Lugo), Fonte-seira (Vilalba, A Terra Chá, Lugo), a freguesía de Santa María de Ambo-sor-es (Muras, A Terra Chá, Lugo), o orónimo Survia (Bretoña, A Pastoriza, A Terra Chá, Lugo), de etioloxía hidronímica, e dúas puntas da costa de Valdoviño e Muros, de nome Sardas e Sargo, respectivamente ${ }^{8}$. Ademais, Bascuas (2008: 530) incorpora formas do léxico común, coma sarabia/saraiba/saragana 'graín-

7 A vacilación entre a vibrante /r/ e a golpeada / / supón un fenómeno constante na toponimia e léxico de carácter prelatino: Garona/Garrona, Caranza/Carranza etc. Para un estudo centrado nesta cuestión cfr. Villar (1993).

8 Sargo tamén pode explicarse a partir do nome do peixe homónimo, frecuente en augas pouco profundas próximas á costa, de xeito semellante a como outros talasónimos reflicten a abundancia de determinadas especies mariñas (A Robaliceira,A Percebeira, A Pedra dos Caramuxos, etc.) (PTG). O mesmo se pode dicir de Sardiñeira, aínda que, de analizarmos o topónimo por esa vía, habería que esclarecer por que un peixe mariño serve de base para designar un curso de auga doce. 
zo, pedrazo', sarro/sarrio 'sedimentos do viño' e surro > xurro 'líquido que solta o esterco' (DRAG; DdD). Esta mesma raíz pode explicar, polo mesmo fenómeno de ultracorrección que cotexamos en Zas (cfr. Martínez Lema 2010: 393-397) e que Bascuas lle supón a Zarzo, o coruñés Ria-zor, aínda que non podemos descartar a hipótese lanzada por Cabeza Quiles (2000: 357-358), segundo a cal o nome deste areal urbano reflicte unha forma *Rio (do) Azor, en referencia á ave de rapina.

Esquematicamente, tendo en conta as puntualizacións arriba comentadas, o indoeuropeo *ser-, *sor- conta en Galicia cos seguintes representantes:

\begin{tabular}{|c|c|c|c|}
\hline & \multicolumn{3}{|c|}{ *SER-, *SOR- 'fluír, discorrer' } \\
\hline & \multirow[t]{2}{*}{ *ser- } & \multicolumn{2}{|c|}{ *sor- } \\
\hline & & *sor- & *sar- $(<*$ sor -$)$ \\
\hline \multirow{6}{*}{ Hidronimia } & \multirow[t]{6}{*}{ Ser } & Sor & Sar \\
\hline & & \multirow[t]{5}{*}{ Sorga } & Sarela \\
\hline & & & Sarria \\
\hline & & & Sardiñeira? \\
\hline & & & Zarzo (< Sartio) \\
\hline & & & Sorga \\
\hline \multirow{3}{*}{ Toponimia } & Monserio & \multirow[t]{3}{*}{ Ambosores } & Sar \\
\hline & Monteseiro & & Sarela \\
\hline & Fonteseira & & Sarria \\
\hline \multirow{3}{*}{ Talasonimia } & & \multirow[t]{3}{*}{ Riazor? (areal) } & Sarga (illa) \\
\hline & & & Sardas (punta) \\
\hline & & & Sargo? (punta) \\
\hline Oronimia & & Survia & \\
\hline \multirow{2}{*}{ Léxico común } & & \multirow[t]{2}{*}{ surro/xurro } & sarabia/sarabia/saragana \\
\hline & & & sarro/sarrio \\
\hline
\end{tabular}

Táboa 8. Representantes da raíz *ser-, *sor- en Galicia.

Moralejo Álvarez (2008: 109) pon en dúbida que o grupo formado pola raíz sar-e o formado por sor- procedan dun mesmo étimo, pois iso suporía entender que ambas series de nomes pertencen a estadios lingüísticos diferentes: os de Sor-, máis antigos, anteriores á confusión entre $\breve{o}$ e $a$; os de Sar-, máis recentes. O autor cre corroborada esta súa sospeita cando se atopa con que a forma medieval do hidrónimo Sor era Saure e variantes (Moralejo Álvarez 2008: 111-112). Con todo, Moralejo Laso (1980: 162) xa advertira de que esas solucións con raíz Saur-constituían falsas latinizacións gráficas. 
Sexa como for, e mesmo que algunhas destas formas poidan explicarse por outras vías (o inventario arriba sinalado non está, en todo caso, pechado), parece sensato acreditar en que *ser-, *sor- callou con forza na nosa terra. Do carácter prelatino desa raíz dá testemuño o nome do río Sar, que xa Pomponio Melo citaba como Sars no século I d.C. (Moralejo Laso 1980: 161). Ademais, contamos con probas epigráficas da enxebreza e antigüidade dunha forma próxima ás que aquí estudamos, Serante, que Leite de Vasconcellos (1931: 167) sitúa nunha lápida atopada en Trásos-Montes, parte constitutiva da antiga Gallaecia. Tendo en conta estas consideracións, coido xustificado remitir os topónimos de base Serant-, medieval Sarant-, a esa mesma raíz indoeuropea, formando grupo con hidrotopónimos coma Sar, Sarela ou Sarria.

Non son, con todo, o primeiro que suxire tal relación; xa Cabeza Quiles (1992: 34) aventurara a devandita etimoloxía para Serantes. Non obstante, a miña proposta encamíñase a considerar que tamén os topónimos de base Sarand-, e mesmo os de base Serand-, proceden desa mesma raíz. A morfoloxía das formas, como veremos a continuación, reforza esta idea.

\subsection{Os sufixo -nt- e -nd-}

Na nosa análise, recoñecemos en Serantes e Serantellos un sufixo -nt- que representa unha das desinencias máis características dos nomes de ríos paleoeuropeos (Bascuas 2002: 28). Ese sufixo conta cunha tradición de estudo abondo delongada. Xa Husbchmid (ELH: 485) se ocupou del, recoñecéndolle valor colectivo cando se trata de apelativos e topónimos e valor amplificativo se é cuestión de hidrónimos. Moralejo Laso (1977: 31), pola súa parte, estuda a cuestión á luz dos representantes galegos da terminación -ntes, como Arantes, Barbantes, Barrantes, Cervantes, Cesantes, Curantes, Ourantes ou o noso Serantes. O profesor leonés afirma, baseándose na lápida de Trás-os-Montes arriba mencionada e na opinión de Vasconcellos (1931: 167), que ese morfema posúe valor étnico ou tribal. Cabeza Quiles (1992: 34) adhírese a esta tese e, recoñecendo en Serantes a mesma raíz hidronímica que neste traballo lle supoñemos, apunta a que o seu sentido etimolóxico é 'habitantes do río, da ribeira ou da lagoa'.

Con todo, as investigacións máis recentes tenden a ver en -nt- un sufixo de ascendencia indoeuropea que ten valor participial, quere dicir, que posúe a función de xerar substantivos e adxectivos a partir de verbos. Así o pensa Moralejo Álvarez (2008: 341) e tamén Bascuas (2002: 28). Esta idea, formulada en base ao método comparativo, non parece imprudente, máxime se temos en conta a coincidencia formal coa desinencia do participio de presente en linguas indoeuropeas antigas ben 


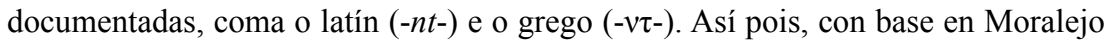
Álvarez e Bascuas, podemos considerar, coas precaucións debidas, que en Serantes sobrevive unha antiga forma participial da raíz verbal *ser-, *sor-.

Tocante aos topónimos de base Sarand-, está xustificado realizar unha análise morfolóxica análoga. Sobre a raíz sar-, seguida da mesma vogal presufixal - $a$ - de Serantes $^{9}$, atopámonos cun sufixo - $n d-$, que podería corresponderse coa desinencia participial - $n t$ - que acabamos de ver. O tema hai que abordalo á luz dun debate máis amplo sobre a sonorización das oclusivas tras nasal ou líquida en material prerromano hispánico, tema aínda suxeito a discusión e que semella lonxe de se esclarecer completamente. Menéndez Pidal atribuía o fenómeno a un substrato osco-umbro no nordés da Península, aínda que el mesmo o detecta fóra dos límites de influencia dese hipotético substrato, nomeadamente en textos leoneses: "a parte septendrionem" (a. 962), "terras... que avemus de parde de... marido nostro" (a. 1027), etc. (Menéndez Pidal 1986: 298). Villar (1995-243-244) considera que a devandita sonorización soborda as estremas espaciais sinaladas por Menéndez Pidal e achega os exemplos dos topónimos Torga, Torgo e Torgados en Galicia e Asturies, na súa opinión provenientes dunha raíz hidronímica Tur- con sufixo -kā- (-ko-), aínda que esas formas tamén poden xustificarse a partir dos apelativos torga 'uz' e torgo 'raíz da uz', talvez dunha forma prerromana * TORǏco (Rivas 1994: 76; Navaza 541-542).

Na estela de Villar, Blanca Prósper (2002: 274) estuda a sonorización do sufixo -nt- a partir do teónimo galaico-lusitano $B a-n d-u e$, que fai derivar dunha forma *Ba-nt-ue). A autora vai máis alá da hipótese de Villar e sinala que a evolución $-n t->-n d$ - é, de feito, un fenómeno norteño anterior á adopción do alfabeto, que se tería estendido a outras zonas da península en etapa xa plenamente histórica. Con todo, en Galicia dispomos dun feixe nada desprezable de topónimos que apunta ao mantemento da oclusiva xorda, entre eles o noso Serantes, pero tamén outros, coma Barbantes, Armentón, Barrantes ou Arentía. Moralejo Álvarez (2008: 144) salva ese escollo argumentando que o material prelatino que presenta oclusiva xorda tras nasal non voceou no paso do latín ao galego, pero que esa evolución si foi posible en época prerromana, e aduce como exemplo o epíteto teonímico galaico-lusitano Toudopala-nd-aigae, fronte a Pala-nt-ico. Pola súa parte, Bascuas (2002: 108; 2006: 78-79, 298-299) pensa que o cambio se orixinou dunha maneira non sistemática, aínda que tampouco infrecuente, e achega un bo número de exemplo que confirman a existencia de $-n d-(<-n t-)$ no territorio da antiga Ga-

9 A vogal temática a (Ser-a-nt-es, Ser-a-nt-ellos) é a máis habitual en concorrencia con sufixo -nt- (Tora-nt-e, Ar-a-nt-e, Gar-g-a-nt-áns), aínda que tamén pode aparecer e (Torr-e-nt-as, Ar-e-nt-ia) (Villar 1995: 217-218). 
llaecia: o hidrónimo Horna-nd-a (Porto do Son, comarca de Noia, A Coruña), de *Orn-a-nt-a, que reflicte un radical paleoeuropeo *er- 'moverse', os apelativos galegos tarandeiraltrandeira, tarandela, tarandear/trondear, tronda, trondieira, trondeiro, os topónimos galegos Tra-nd-eira e Tra-nd-eiras, este tamén presente en Portugal, o portugués Tra-nd-es, o asturiano Tara-nd-ielles e o hidrónimo Tala-nd-a (provincia de Zamora), todos eles provenientes dunha raíz paleoeuropea *ter-, *tar- 'fregar, atravesar'.

Téñase en conta que - $n t$ - e - $n d$ - son característicos de formacións hidronímicas indoeuropeas, do mesmo xeito que o é a desinencia secundaria -ón que manifesta Sar-a-nd-ón, como veremos (cfr. epígrafe 4.5). Se a isto sumamos a forteleza da raíz ser-, sor- en Galicia e a existencia de casos análogos de -nd-<-nt- (Hornanda, Trandeira, tarandela, etc.), podemos afirmar que a base Sarand- supón un exemplo de sonorización esporádica en territorio galego da desinencia - $n t$-, sufixo que en Serantes e Serantellos se conserva na súa forma regular, isto é, con oclusiva xorda, de xeito paralelo ao que acontece en Asturies con Les Tara-nd-ielles (Priesca, Villaviciosa) fronte a Tara-nt-iellos (Miñu, Tinéu).

\subsection{A base Serand- (Serandías, Serandi)}

Ademais de Serant- e Sarand-, sabemos que existe unha base Serand-, con vogal pretónica anterior e oclusiva sonora tras nasal, que se manifesta no asturiano Serandi e no eonaviego Serandias. Seguindo a estela de Krahe e Bascuas, entendemos que o semema 'fluír, discorrer' se manifesta en antigo europeo nunha raíz con dous significantes distintos, un con vogal velar $\left({ }^{*}\right.$ sor- e, cando el, *sar-) e outra con vogal palatal (*ser-). Así pois, mentres que Serant- (medieval Sarant-) e Sarand- proceden do primeiro, Serandi e Serandias faríano do segundo.

\begin{tabular}{|c|c|c|}
\hline \multicolumn{3}{|c|}{ *SER-, *SOR- 'fluír, discorrer' } \\
\hline \multirow{2}{*}{ *ser- } & \multicolumn{2}{|c|}{ *sor- } \\
\hline & *sor- & ${ }^{*}$ sar- $\left(<*_{\text {sor }}\right)$ \\
\hline Serandi & & Sarandeses \\
\hline Serandias & & Sarandín \\
\hline \multirow[t]{4}{*}{ ant. Serante } & & Sarandón \\
\hline & & Sarandós \\
\hline & & Serantes $(<$ Sarantes $)$ \\
\hline & & Serantellos $(<$ Sarantellos $)$ \\
\hline
\end{tabular}

Táboa 9. Toponimia de base Serant-, Sarand- e Serand- á luz da variante fonética do radical paleoeuropeo de que proceden. 
Da existencia desa segunda variante con vogal anterior no territorio da antiga Gallaecia dan fe hidrónimos como Ser e topónimos como Monserio (cfr. epígrafe 4.2). $\mathrm{Na}$ táboa incorporamos aquel Serante que Vasconcellos sitúa nunha lápida transmontana no apartado dos representantes do resultado palatal. Contra a opinión do erudito portugués (Vasconcellos 1931: 167), nós entendemos que esa antiga forma non se corresponde exactamente co moderno Serantes, pois, como vimos, este procede por disimilación dunha antiga base Sarant- que os textos da Idade Media reflicten. En consecuencia, os actuais Serantes e Serantellos comparten cos de base Sarand- a ascendencia da variante velar do radical, mentres que ese antigo Serante remite, coma Serandi e Serandías, á solución palatal. Repárese, ademais, en que os dous resultados da raíz, anterior e posterior, dispoñen de representantes con sufixación primaria - $n t$ - e tamén con -nd-.

A presenza da desinencia secundaria -ías en Serandias, impropia en todo dun antropotopónimo, irmanda ese nome de lugar con outros coma Sarandín ou Sarandón, o que suxire unha procedencia delexical. Con todo, esa orixe non é tan clara en Serandi, cuxa terminación si parece evocar un antigo nomen possessoris. Como vimos, García Arias (2005: 480, 482, 508) postula un étimo *(VILLA) SERANDI, dun antropónimo latino SERANDIUS recollido por Solin/Salomies. A proposta, en principio, parece verosímil, aínda que conta con algúns problemas, como xa comentamos (cfr. epígrafe 3.2). A favor da etimoloxía delexical paleoeuropea, pola contra, fala a documentación antiga da vila, pois nun documento datado no ano 891 conviven as variantes gráficas $<$ Serandi $>$ ou $<$ Serandi $>$ con $<$ Seranti $>$ (CODOLGA). É dicir, recóllese con oclusiva sonora, pero tamén xorda, o que nos fai pensar no mesmo sufixo - nt-> -nd- que se atopa en Serantes ou Sarandón. Ademais, parece sensato pensar que o nome da vila procede do río homónimo que transcorre por ela, e non ao revés, dado o carácter máis antigo da hidronimia, o que semella apuntalar o sentido hidronímico da forma. Todos estes factores animan a ver, tamén en Serandi, un representante da raíz *ser-, *sor- e, consecuentemente, a agrupalo canda Serandías e os demais topónimos de base Serant- e Sarand-.

\subsection{As desinencias secundarias}

A continuación presentamos unha análise etimolóxica e semántica das desinencias secundarias que reflicten estes topónimos. Cando sexa posible, tentaremos achegar tamén algunhas notas sobre a etioloxía das formas á luz das súas desinencias.

-ellos (Ser-a-nt-ellos). Serantellos reflicte o sufixo diminutivo latino -ICULos, que se corresponde co portugués -elhos, asturiano e leonés -eyos e español-ejos. Entra cedo 
na lingua e axiña deixa de ser produtivo ${ }^{10}$, quedando lexicalizado (cortello 'corte' $<$ corte), o que garante a antigüidade do topónimo, que rexistramos desde o ano 934 (Alonso Núñez 2000: 11; CODOLGA). Os dous lugares chamados Serantellos que rexistramos en Galicia poden explicarse a partir doutras tantas entidades de nome Serantes. Así, o Serantellos de Ferrol xorde como diminutivo do nome da parroquia que o abrangue, isto é, San Salvador de Serantes, como acontece cos casos de Rianxiño, parroquia de Santa Comba de Rianxo, ou Bergondiño, freguesía de San Salvador de Bergondo. Pola súa parte, o Serantellos de Santa Cruz de Castrelo (Cambados, O Salnés, Pontevedra) debe proceder do veciño lugar de Serantes (San Xoán de Baión, Vilanova de Arousa, O Salnés, Pontevedra).

-es (Ser-a-nt-es). De acordo coa análise que vimos de efectuar, -es non pode entenderse como parte dunha desinencia máis ampla -ntes (Barbantes, Arantes, Ourantes, Barrantes), como cría Moralejo Laso (1977: 31), senón que ten entidade morfolóxica propia. De acordo con Villar (1995: 194, 206, 213), interpretámolo como morfema de nominativo singular dun tema en -i- (FINIS, -IS), modalidade flexiva que presentan moitos hidrónimos da Hispania prerromana, incluídos os galegos estudados por Moralejo Laso e que nesta análise morfolóxica quedarían xebrados como Bar(-)b-a-nt-es, Ar-a-nt-es, Our-a-nt-es, Barr-a-nt-es. Deste punto de vista, Serantes $(<*$ SERANTIS, -IS), solución plenamente prerromana adaptada ao sistema flexivo do latín, non constituía no seu tempo unha forma plural, mais iso non impediu que fose interpretada como tal á hora de xestar, xa en época romance, o derivado Serant-ellos, e non *Serant-ello, o cal indica que a conciencia da lingua orixinal que deu como resultado o topónimo primario se perdera.

-eses (Sar-a-nd-eses). Trátase do sufixo popular -eses, irmán do culto -enses, do latín -ENSES, que tiña a mesma función de derivar adxectivos xentilicios e de pertenza a base de topónimos (hispāni-ensis 'hispano' < Hispānia, -ae 'Hispania') (Pharies 2002: 233). Sarandeses (Santaia de Rairiz, Santiso, Terra de Melide, ACoruña) é, polo tanto, un nome de lugar que reflicte un movemento de poboación desde algún punto de nome Sarand(talvez algún dos Sarandón de Vedra?) a ese lugar de Santaia de Rairiz. A creación de nomes de lugar a partir de xentilicios é un fenómeno frecuente na toponimia, como ilustran os exemplos Sarreaus (A Limia, Ourense) 'naturais de Sarria', (San Martiño de) Cumbraos (Monterroso, Ulloa, Lugo) 'oriúndos de Coimbra' ou Fondoreses (Santiago de Requeixo, Chantada, comarca de Chantada, Lugo) 'naturais de Fondedor'11.

10 Alonso Núñez (2000: 11) recolle unha información que lle achega Antón Santamarina segundo a cal o sufixo se mantén vivo na Fonsagrada con valor despectivo: nenello.

11 Outros exemplos de topónimos derivados de xentilicios en Navaza (2002: 142) e Sánchez Rei (2011: 491-492). 
-ías (Ser-a-nd-ías). A hipótese antroponímica de García Arias a propósito de Serandias, dificilmente xustificable en termos de evolución lingüística (cfr. epígrafe 3.2), pode salvarse se vemos nese -ías o resultado característico do galego eonaviego para o sufixo diminutivo procedente do latín -īNUS, -A, -UM, que deu no galego común o resultado -iño/s, -iña/s. No galego de Asturies, a forma feminina plural desa desinencia é, precisamente, -ías (Fernández Rei 1991: 64). Tamén cabe remitilo ao latín *-īA, forma vulgar do clásico -ǏA, que sobrevive en solucións do léxico común tales como monxía ou freiría e en topónimos como Muxía (Martínez Lema 2010: 250). Aínda, determinadas formas de aparencia prerromana presentan un final -ía, con toda probabilidade tamén prelatino, que talvez se corresponda co de Serandías: Buría, Buía, Oría... Esta última hipótese é especialmente rechamante, pois trataríase da mesma terminación que aparece en Ser-ía (San Cristovo de Dormeá, Boimorto, comarca da Arzúa, A Coruña), topónimo que debe reflectir unha construción análoga desde a raíz * ser- sen sufixación primaria -nt-.

-ín (Sar-a-nd-ín). Sarandín é o topónimo desta familia máis difícil de abordar dun punto de visto morfolóxico, dado que a terminación -ín lle dá aparencia de nomen possessoris, na liña de Amorín, do antropónimo latino Amorinus, ou Mundín, do nome xermánico MONDINUS. Con todo, a hipótese lanzada nesa dirección por Piel/ Kremer parece altamente especulativa e conta na súa contra coa presenza documental (cfr. epígrafe 3.2). Sen posibilidade de remitir o topónimo a ningún antropónimo prerromano, latino ou xermánico coñecido, o máis sensato semella consideralo delexical e irmandalo cos demais nomes de base Sarand-. De feito, ese -ín ben puidera ser o mesmo diminutivo -ín, feminino -ia, que suxerimos para Serandias en primeiro termo. O problema que se nos presenta é que o lugar de Sarandín (San Fiz do Barón, O Carballiño, comarca do Carballiño, Ourense) e os dous terreos homónimos de Santiago de Anllo (San Amaro, comarca do Carballiño, Ourense) localízanse no dominio xeolectal de -iño (ALGA II: 106-107; Fernández Rei 1991: 64). Con todo, en zonas de -iño, atopamos esporadicamente a solución -ín fosilizada na toponimia: Curutín (Santa María Madalena de Sobrada de Aguiar, Outeiro de Rei, comarca de Lugo, Lugo), Valín (Santalla de Bóveda de Mera, Lugo, comarca de Lugo, Lugo) ou Penaporrín (Santa María de Loimil, A Estrada, Tabeirós-Terra de Montes, Pontevedra) (Bascuas 2005: 82). Tamén Navaza (2006: 526) recolle o topónimo Soutín fóra da zona oriental. Non sería insólito, pois, que Sarandín reflectise un resultado anómalo de -īNus e pasase a engrosar esa lista de excepcións. Sería interesante abordar un estudo sistemático dos resultados do latín -īnus na toponimia e cruzalos cos datos que nos achega a dialectoloxía. As conclusións que dese traballo se tirasen poderían servir para explicaren a suposta anomalía que presenta Sarandin. 
-ón (Sar-a-nd-ón). Malia o que nunha primeira ollada poida parecer, cremos que non se trata do aumentativo que se manifesta as formas coma cabez-ón, cord-ón ou barrig-ón. Na liña do visto a propósito de -es en Serantes, de acordo con Villar (1995: 194-195), Sarandón debe reflectir a adaptación dunha forma paleoeuropea ao sistema nominal do latín, a través da modalidade flexiva dun tema en -ONIS, -ONIS ou ben en -O, -ONIS. Deste xeito, o topónimo sería herdeiro dunha forma acusativa *Sarandone $(m)$. En cambio, se seguimos a Martínez Lema (2010: 151), habemos ver nese -ón un sufixo prelatino -ōNE, paradigmático de denominacións toponímicas adscribibles ao antigo europeo, como Avión, Dozón ou Arón. De ser así, trataríase probablemente dun sufixo derivativo que xera substantivos de acción a partir de verbos, a xulgar polo carácter verbal da meirande parte dos radicais con que concorre ${ }^{12}$, como acontece co seu homónimo latino (regiōo, -ōnis 'dirección' < regō, -ere 'dirixir') (Pharies 2004: 163-164), co cal talvez veña confluír na árbore xenética indoeuropea. Sexa cal sexa a orixe da desinencia, é indubidable a filiación hidronímica da maior parte das formas con que aparece, dato que temos que tomar como unha proba máis da etimoloxía que para Sarandón e a súa familia toponímica presentamos neste traballo.

-ós (Sar-a-nd-ós). Sarandós, pronunciado con vogal tónica media-pechada [o], debe reflectir a mesma desinencia ca Sarand-ón en plural (< ŌNES), co resultado -ós característico do bloque central (ALGA II: 84-85, III: 298-299; Fernández Rei 1991: 66-67), onde debemos situar o lugar de Sarandós (San Román de Montoxo, Cedeira, comarca da Coruña, A Coruña) e a freguesía de Santa María de Sarandós (Abegondo, comarca de Ferrol, A Coruña). A documentación medieval reforza esta idea: Sancte Marie de Serandones, a. ca. 1229 (CODOLGA).

\section{Conclusións}

O proceso de investigación que levou á publicación deste traballo orientouse en dúas direccións complementarias: unha primeira, dirixida a desbotar con argumentos lingüísticos as distintas hipóteses etimolóxicas que coincidían en sinalar o carácter deantroponímico dos nomes de lugar de base Serant- e Sarand-; a segunda, encamiñada a propoñer unha etimoloxía alternativa que remitise a unha forma do léxico prerromano. Ambos os obxectivos retroalimentáronse e serviron para confirmar as conclusións que se ían tirando dun e doutro lado.

12 Vallan como exemplo os casos de Ardab-ón e Ar-ón, do indoeuropeo *er- 'moverse, fluír' ou Gurgull-ón, de *gwer- 'tragar' (Bascuas 2002: 59, 329) 
A primeira tarefa levounos a realizar unha pescuda de hipóteses etimolóxicas vertidas en estudos toponomásticos solventes. Dese percorrido extraemos achegas desde os albores da lingüística galega, coa opinión do padre Sarmiento, á máis recente contemporaneidade. Salvando as contribucións de Sarmiento e de Frutos Fernández, a maior parte dos autores pensou nestas formas como redutos de antigos nomes de propietarios rurais. Mais a análise detallada desas formulacións, así como a realidade documental e lingüística de cada unha das formas, obrigounos a rexeitar ese tese. Os argumentos que atopamos en contra dunha orixe antroponímica para estes topónimos pódense resumir nas seguintes tres epígrafes:

a) A imposibilidade, do punto de vista da lingüística diacrónica, de remitir a etimoloxía de cada unha destas solucións a outros tantos antropónimos, ora latinos, ora xermánicos;

b) A escaseza de documentación que avale a existencia deses supostos étimos antroponímicos ou, cando menos, do seu uso efectivo no territorio da antiga Gallaecia;

c) A mesma morfoloxía dos nomes, con sufixación secundaria abondo recoñecible (-ón, -ós, -ellos, etc.), que suxire unha etimoloxía delexical.

Rexeitada a hipótese deonomástica por incongruente, a investigación enfocouse a achegar datos que falan a prol dunha orixe compartida para cada un dos topónimos obxecto de análise, orixe que, na nosa proposta, asenta na raíz indoeuropea *ser-, *sor- 'fluír, discorrer'. Eses argumentos son, en resumo, os seguintes:

a) A existencia de probas epigráficas que demostran o carácter prelatino destas bases;

b) A abundancia de representantes en Galicia do radical indoeuropeo *ser-, *sor'fluír, discorrer';

c) A presenza dun sufixo (-nt->-nd-) característico das formacións prelatinas e, máis especificamente, das hidronímicas;

e) A existencia de desinencias secundarias paradigmáticas de construcións hidronímicas indoeuropeas (-es, -ón). 


\section{Referencias bibliográficas}

ALGa II = Instituto da Lingua Galega [1995]: Atlas Lingüistico Galego. V. II: Morfoloxía non verbal ([A Coruña]: Fundación Pedro Barrié de la Maza).

ALGa III = Instituto da Lingua Galega [1995]: Atlas Lingüístico Galego. V. III: Fonética ([A Coruña]: Fundación Pedro Barrié de la Maza).

Alonso Núñez, A. S. (2000): “Os sufixos nominais diminutivos do galego actual”, Verba 27, 133-174.

Bascuas, E. (2002): Estudios de hidronimia paleoeuropea gallega. Anexo $51 \mathrm{de}$ Verba (Santiago de Compostela: Universidade de Santiago de Compostela).

Bascuas, E. (2006): Hidronimia y léxico de origen paleoeuropeo en Galicia (Sada: Ediciós do Castro).

Bascuas, E. (2008): "La hidronimia de Galicia. Tres estratos: paleoeuropeo, celta y latino", Estudios Mindonienses 24, 521-550.

Cabeza Quiles, F. (1992): Os nomes de lugar. Topónimos de Galicia: a súa orixe e o seu significado (Vigo: Xerais).

Cabeza Quiles, F. (2000): Os nomes da terra. Topónimos galegos (Noia: Toxosoutos).

Dauzat, A. (dir.) (1978): Dictionnaire étymologique des noms de rivières et de montagnes en France (París: Klincksieck).

DCECH = Corominas, J. / Pascual, J. A. (1991): Diccionario crítico etimológico castellano e hispánico, 6 v. (Madrid: Gredos).

DMadoz = Madoz, P. (1846-1850): Diccionario geográfico-estadístico-histórico de España y sus posesiones de ultramar, 16 v. (Madrid: $2 \backslash \mathrm{sa} \backslash \mathrm{p}$ ed).

ELH = Alvar, M. (dir.) (1960): Enciclopedia lingüística hispánica. I: Antecedentes. Onomástica (Madrid: Consejo Superior de Investigaciones Científicas).

Fernández González, F. (2007): Nomes do Ribeiro ([Galicia]: Instituto de Estudios Carballiñeses).

Fernández Rei, F. (1991): Dialectoloxía da lingua galega (Vigo: Xerais).

Frías Conde, X. (2002): “O elemento árabe en galego (II)”, Revista Galega de Filoloxía 3, 65-80.

García Arias, X. L. (2005): Toponimia asturiana: el porqué de los nombres de nuestros pueblos (Oviedo: Prensa Asturiana). 
Hermo González, G. (2013): “Toponimia maior da parroquia de Taragoña (Rianxo, O Barbanza). Estudo etimolóxico”, Estudos de Lingüística Galega 5, 43-67.

HGNB = Piel, J. M. / Kremer, D. (1976): Hispano-gotisches Namenbuch (Heidelberg: Carl Winter).

Kajanto, Iiro (1982): The Latin Cognomina (Roma: Giorgio Bretschneider Editore).

Krahe, Hans (1964): Unsere ältesten Flussnamen (Wiesbaden: Harrassowitz).

Vasconcellos, J. Leite de (1931): Opúsculos. III: Onomatologia (Coimbra: Imprensa da Universidade).

Martínez Lema, P. (2010): A toponimia das comarcas de Bergantiños, Fisterra, Soneira e Xallas na documentación do Tombo de Toxos Outos (séculos XII-XIV). USC. Tese de doutoramento inédita. Dispoñible en http://dspace.usc.es/bitstrea m/10347/2870/1/9788498875782_content.pdf [consult. 01.03.2013].

Menéndez Pidal, R. (1986): Orígenes del español: estado lingüístico de la Península Ibérica hasta el siglo XI (Madrid: Espasa-Calpe).

Moralejo Álvarez, J. J. (2008): Callaica Nomina. Estudios de Onomástica Gallega ([A Coruña]: Fundación Pedro Barrié de la Maza).

Moralejo Álvarez, J. J. (2009): "Hidronimia perromana de Gallaecia", en Kremer, D. (ed.): Onomástica galega II: onimia e onomástica romana e a situación lingüistica do noroeste peninsular. Anexo 64 de Verba (Santiago de Compostela: Universidade de Santiago de Compostela).

Moralejo Laso, A. (1977): Toponimia gallega y leonesa (Santiago de Compostela: Pico Sacro).

Moralejo Laso, A. (1980): "Notas acerca de hidronimia gallega", Verba 7, 157-170.

Navaza, G. (2006): Fitotoponimia galega ([A Coruña]: Fundación Pedro Barrié de la Maza).

Navaza, G. (2007): Toponimia de Catoira (Catoira: Concello de Catoira).

Navaza, G. (2011): “Galicia”, en García Arias, X. Ll. (coord.): Toponimia hispánica. Origen y evolución de nuestros topónimos más importantes: 13-36 (Valencia: Denes).

Navaza, G. (2002): “Dialectoloxía e onomástica”, en Álvarez, R. / Dubert García, F. / Sousa Fernández, X. (eds.): Dialectoloxía e léxico: 137-146 (Santiago de Compostela: Consello da Cultura Galega / Instituto da Lingua Galega).

OELG = Sarmiento, M. (1999): Onomástico etimológico de la lengua gallega, 2 v. ([A Coruña]: Fundación Pedro Barrié de la Maza). 
Pharies, D. A. (2002): Diccionario etimológico de los sufijos españoles y de otros elementos finales (Madrid: Gredos).

Pharies, D. A. (2004): “Tipología de los orígenes de los sufijos españoles”, Revista de Filología Española 84: 153-167.

Piel, J. M. (1984): "Novíssimas achegas à história da tradição antropo-toponomástica mais antiga latina no Noroeste galaico", Verba 11, 5-24.

Prósper, B. M. (2002): Lenguas y religiones prerromanas del occidente de la Península Ibérica (Salamanca: Universidad de Salamanca).

Rivas, E. (1994): Lingua galega, nivéis primitivos (Santiago de Compostela: Laiovento).

Sánchez Rei, X. M. (2011): Lingua galega e variación dialectal (Santiago de Compostela: Laiovento).

Varela Aenlle, C. X. (2000): Toponimia del Eo-Navia (Eilao, Asturias: Mesa prá Defensa del Galego de Asturias).

Villar, F. (1993): “Termes, Tarraco, Turiasu. Los dobletes con $r / r r$ en la toponimia prerromana hispana", Beiträge zur Namenforschung 28: 301-339.

Villar, F. (1995): Estudios de celtibérico y de toponimia prerromana (Salamanca: Universidad de Salamanca).

\section{Recursos na rede}

CAG = Boullón Agrelo, A. I. / Sousa Fernández, X. (dirs.) (2006): Cartografía dos apelidos de Galicia. Santiago de Compostela: Instituto da Lingua Galega. Dispoñible en http://ilg.usc.es/cag/ [consult. 24.01.2013].

CODOLGA = López Pereira, J. E. (1994-): Corpus Documentale Latinum Gallaeciae. Santiago de Compostela: Centro Ramón Piñeiro para a Investigación en Humanidades. Dispoñible en http://corpus.cirp.es/codolga/ [consult. 13.01.2013].

DRAG = Real Academia Galega (2012): Dicionario da Real Academia Galega. A Coruña: Real Academia Galega. Dispoñible en http://www.realacademiagalega.org/dicionario\#inicio.do [consult. 07.02.2013].

DdD = Santamarina, A. (dir.) (2003): Diccionario de diccionarios. A Coruna: Fundación Barrié de la Maza. Dispoñible en http://sli.uvigo.es/ddd/index.html [consult. 18.022013].

ITGM = Varela Barreiro, X. (dir.) (2008-): Inventario Toponímico da Galicia Medieval. Santiago de Compostela: Instituto da Lingua Galega. Dispoñible en http:// ilg.usc.es/itgm/ [consult. 31.01.2013]. 
$\mathrm{NG}=$ Comisión de Toponimia da Xunta de Galicia (2004): Nomenclátor de Galicia . Toponimia oficial das provincias, concellos, parroquias e lugares. Santiago de Compostela: Xunta de Galicia. Dispoñible en http://www.xunta.es/nomenclator/ busca.jsp [consult. 25.01.2013].

PTG = Comisión de Toponimia da Xunta de Galicia (2000-): Proxecto Toponimia de Galicia (microtoponimia). Santiago de Compostela: Xunta de Galicia. Dispoñible en http://sitgaideg.xunta.es/buscadoravanzado/ [consult. 14.12.2013].

TMILG = Varela Barreiro, X. (dir.) (2004-): Tesouro Medieval Informatizado da Lingua Galega. Santiago de Compostela: Instituto da Lingua Galega. Dispoñible en http://ilg.usc.es/tmilg [consult. 01.03.2013].

$V B O=$ Acevedo y Huelves, B. / Fernández y Fernández, M. (1932): Vocabulario del bable de occidente (Madrid: Centro de Estudios Históricos).

- $V G=$ Sarmiento, M. (1975): Viaje a Galicia, en Pensado Tomé, J. L. (ed.) (Salamanca: Universidad de Salamanca).

- $\quad V P G C=$ Filgueira Valverde, X. et al. (1926): Vocabulario Popular GalegoCastelán (Santiago de Compostela: Seminario de Estudios Galegos).

Sanz Alonso, B. (1997): Toponimia de la provincia de Valladolid. Las cuencas del Duero, Pisuerga y Esgueva (Valladolid: Universidad de Valladolid).

TMILG = Varela Barreiro, X. (dir.) (2004-): Tesouro Medieval Informatizado da Lingua Galega (Santiago de Compostela: Instituto da Lingua Galega). [http:// ilg.usc.es/tmilg].

Varela Sieiro, X. (2008): Léxico cotián na Alta Idade Media de Galicia: arquitectura civil. Anexo 62 de Verba (Santiago de Compostela: Universide de Santiago de Compostela).

Vázquez Fernández, M. I. (1971): El habla y el léxico de Pereiramá (Lugo). Tese de licenciatura inédita (Santiago de Compostela: Universidade de Santiago de Compostela).

Vázquez Santamarina, M. E. (1971): El habla de La Gudiña. Tese de licenciatura inédita (Santiago de Compostela: Universidade de Santiago de Compostela).

Villar Liébana, F. (2000): Indoeuropeos y no indoeuropeos en la Hispania prerromana: las poblaciones y las lenguas prerromanas de Andalucía, Cataluña y Aragón según la información que nos proporciona la toponimia (Salamanca: Ediciones Universidad de Salamanca).

Xunta de Galicia (2003): Nomenclátor de Galicia. Dispoñíbel en <http: //www. xunta.es/toponimia $>$ [consult. 19/12/2011]. 